\title{
0 sonho acabou? 0 governo Lula nos principais jornais italianos
}

\section{RESUMO}

O presente artigo descreve e analisa títulos e alguns textos mais expressivos publicados sobre o presidente brasileiro, Luiz Inácio Lula da Silva, nos principais jornais diários italianos - la Repubblica e Corriere della Sera, de outubro de 2002, em ocasião da sua eleição, até agosto de 2005, quando se revelou a crise política. O objetivo principal é conectar o conceito de "transformação de visibilidade" (Thompson, 1998) com o governo Lula a fim de compreender o impacto da mídia na construção da visibilidade e das relações de poder.

\section{PALAVRAS-CHAVE}

- comunicação política

- imprensa italiana

- visibilidade

\section{ABSTRACT}

This research proposes to analyse titles and some articles published about Lula's government in the principles quality newspapers in Italy - la Repubblica e Corriere della Sera, from October 2002, when the President was elected, until August 2005. The main objective is to connect the concept of "transformation of visibility" - in The media and modernity (Thompson, 1998) - with Lula's government in order to understand the media impact in the visibility construction and the power relations.

\section{KEY WORDS}

- political communication

- Italian press

- visibility

\section{Jamile Dalpiaz}

Universidades de Florença e Londres oportunidade de acompanhar a eleição e parte do governo de Luiz Inácio Lula da Silva através da mídia européia permitiu-me realizar algumas reflexões sobre a relação entre a imprensa e a política. Observar o Brasil na pauta italiana foi um estímulo a buscar compreender o papel que este país vem desempenhando no cenário internacional. O significativo espaço e a visibilidade dedicada ao governo brasileiro através da figura do presidente Lula, por meio de informações elaboradas por correspondentes enviados especialmente para tal fim, demonstram mudanças no modo no qual os europeus observam a política de um país latino-americano. Diante disso, vieram os questionamentos: seria este um sinal de que o mundo globalizado está dando visibilidade à vida política brasileira incluindo o país na sua lógica de mercado? Ou trata-se de um excessivo otimismo por parte dos observadores europeus diante das promessas de diminuição da desigualdade social?

Em janeiro de 2003, Lula tornou-se o primeiro presidente brasileiro proveniente da classe dos trabalhadores, prometendo fortes mudanças sociais. Um dos seus principais programas de governo foi o chamado Fome Zero, através do qual estabelecia que, ao término de seu mandato, em 2006 (N.R. Na verdade, primeiro mandato, pois ele acabou sendo reeleito em novembro de 2006 para mais quatro anos no cargo), teria assegurado a todos os brasileiros, pelo menos, três refeições por dia. Passados poucos meses de gestão, o referido projeto não deslanchou, ainda que os indicadores econômicos tivessem, imediatamente após a eleição, se estabilizado gradualmente. Mas isso foi possível não somente porque Lula manteve as promessas de realizar um governo moderado, mas também porque surpreendeu o país adotando um percurso mais conservador do que o seu antecessor, Fernando Henrique Cardoso.

Observando as reportagens publicadas sobre o início do governo Lula nos principais jornais diários da Itália la Repubblica e Corriere della Sera ${ }^{1}$ verificou-se que o cenário externo, neste caso o italiano, descrevia a política brasileira de uma perspectiva otimista. Fenômeno este compartilhado pela mídia européia de modo geral, pois os principais jornais europeus, até bem pouco tempo atrás, apresentavam o presidente Lula quase como um "pop star". Os títulos publicados em diferentes diários demonstram esta característica: Brazil's new leader shelves warplanes to feed hungry (The Guardian, 03/01/2003); Lula begins campaign to champion the poor (The Times, 13/01/2003); Lula da Silva asume la presidencia de Brasil y promete luchar contra el hambre en el país (El Mundo, 01/01/2003); Lula apuesta por un nuevo modelo economico para combatir 
con eficacia el hambre y la probreza (El Pais, 26/01/ 2003); Le 'premier' president d'origine populaire, un modelo pour la gauche latino-americaine (Le Figaro, 31/12/ 2002); Au Brésil, le nouveau style de la 'Republique da Silva' (Le Monde, 31/12/2002). Estes jornais ilustraram também a participação de milhares de pessoas em fóruns sociais, em conferências e visitas oficiais de Lula ao Velho Mundo, manifestando consenso ao presidente brasileiro por figurar como protagonista da antiglobalização. É oportuno ressaltar, neste sentido, que o Brasil vem recebendo espaço com matérias especiais na mídia européia em qualidade e quantidade $^{2}$ significativas, na maioria das vezes produzidas por correspondentes e não simplesmente por agências de notícias. ${ }^{3} \mathrm{O}$ jornal Corriere della Sera registrou no seu banco de dados 303 matérias publicadas sobre Lula e/ou seu governo, de 1o de outubro de 2002 a 31 agosto de 2005. Já o periódico la Repubbica, 143 textos em igual período.

Os estudos de comunicação demonstram que, desde os anos 90, a relação entre a comunicação e a política tem se transformado. Argumentam não ser mais possível observar os meios de comunicação como mera técnica, com textos prontos a convencer os eleitores da bondade da oferta política. A comunicação representa, nos dias de hoje, um "lugar" de definição de um modo diferente de se fazer política, que considera o cidadão das sociedades contemporâneas mais exigente em comparação àqueles do passado; pois solicitam constantemente provas concretas sobre a confiança dos interlocutores políticos (SORRENTINO, 2001; RUBIM, 2000).

A presente pesquisa versa sobre este tema e busca identificar elementos que possam servir de ponto de partida para uma análise mais aprofundada sobre o porquê de a imprensa européia, neste caso a italiana, dedicar espaço e visibilidade à política de um país latino-americano. Ao descrever e analisar os títulos e alguns textos mais expressivos publicados sobre o governo Lula nos diários italianos Corriere della Sera e la Repubblica, de outubro de 2002 a agosto de 2005, este artigo limitou-se a contextualizar os três períodos identificados em ambos jornais, ainda que apresentem propostas editoriais diferentes. A primeira fase contempla a eleição e a posse do novo governo, que apresenta uma visão otimista. A segunda abrange os anos intermediários de 2003 a 2005, momento de questionamentos sobre as ações sociais e economia. Uma terceira revela a crise política.

Para contextualizar a cobertura destes diários, através dos títulos publicados sobre o presidente Lula, foi necessário perseguir as seguintes perguntas: como o governo brasileiro é identificado? qual o enfoque mais abordado: as ações de políticas sociais ou econômicas?

No Brasil verificou-se uma situação paradoxal. Embora a crise política, instaurada em junho de 2005 por denúncias de corrupção que envolve a equipe de governo, tenha abalado a imagem de Lula, o presidente brasileiro mantinha um expressivo índice de aprovação, ainda que este tenha diminuído se relacionado ao registrado no início do governo. Os números da pesquisa CNT/Sensus divulgada recentemente revelam que, em janeiro de 2003, $87,6 \%$ aprovavam o desempenho do presidente e somente $6,8 \%$ desaprovavam. A mesma pesquisa aplicada no início de setembro de 2005 aponta 50\% de aprovação e 39,4\% de desaprovação. ${ }^{4}$ Significa dizer que os brasileiros continuam esperançosos por mudanças e apostando no governo de um membro da classe pobre do país.

Para vencer as eleições de 2002, o Partido dos Trabalhadores (PT) construiu e redefiniu a imagem de Lula, principalmente, naquilo que se referia ao modo de se apresentar diante os meios de comunicação. Auxiliado por uma forte campanha de marketing político, a qual preservou elementos de sua identidade, ou seja, de um representante da pobreza, Lula reforçou a sua imagem como perfeito porta-voz da classe menos favorecida brasileira. ${ }^{5}$ De fato, a primeira ação do PT foi aquela de trabalhar sobre a identidade brasileira, pois os integrantes do partido compreenderam a necessidade de mudanças depois de três tentativas de eleição enfrentadas por Lula e seguidas por derrotas. Neste sentido, é interessante ressaltar que a comunicação política aponta que o emissor, antes de comunicar aos outros suas mensagens e intenções, deve conhecer bem a sua própria identidade - quem é e quais valores inspiram as suas ações -, definindo, assim, os seus objetivos e indicando como pretende alcançá-los (SORRENTINO, op.cit., p. 13). Para a eleição de Lula o PT contratou o renomado publicitário, Duda Mendonça, que recriou a imagem do candidato redefinindo os aspectos mais radicais e o modo de se apresentar na mídia. Como resultado, Lula obteve uma imagem positiva e visibilidade, conquistando maior número de eleitores. Estes elementos nos induzem a pensar que a imprensa é, também, um agente ativo na criação de significados. Através da produção de notícias, estabelece competências e transforma-se em agente ativo do jogo político.

Sobre este aspecto, Thompson (1998) ajuda a compreender o significado da visibilidade de Lula na imprensa italiana. $\mathrm{O}$ autor propõe, neste sentido, que se deveria colocar a reinvenção da esfera pública em um ambiente simbólico que, de um lado, caracteriza-se por uma grande concentração de recursos e, de outro, se estende além das fronteiras dos Estados-nação.

Destaca Thompson (p. 14) que o desenvolvimento dos meios de comunicação não apenas tornou visível o poder de modo diferente, mas também, o fez mais forte, isto é, a visibilidade hoje disponibilizada pela mídia é efetivamente global. A globalização da comunicação se vinculou a outros processos de desenvolvimento constitutivos das sociedades modernas e, por isso, se deve considerar os contextos particulares internos nos quais os produtos da mídia globalizada são recebidos e interpretados.

Portanto, esta pesquisa sobre o governo brasileiro nos principais jornais diários da Itália será desenvol- 
vida também partindo de algumas referências inspiradas na perspectiva de Thompson que se ocupa da interpretação contextualizada das formas simbólicas, neste caso, a cobertura jornalística através dos títulos publicados no referido período.

Carnaval e samba, violência e tráfico de seres humanos, futebol, Amazônia e favelas foram e continuam sendo pautas sobre o Brasil na mídia italiana. No entanto Lula, sem dúvida, colocou em evidência uma outra perspectiva, aquela de unir o mundo pobre ao rico, passando por interlocutor.

Esta pesquisa descreve a seguir a trajetória de Lula neste período limitando-se a contextualizar, por meio dos títulos publicados, a história contada pelos principais cotidianos italianos. A análise qualitativa será situada a partir da categoria "transformação da visibilidade" descrita por Thompson ao buscar compreender o impacto da mídia sobre a natureza da publicidade e as relações entre poder e visibilidade. Este autor considera que, antes dos meios de comunicação, os eventos públicos eram espetáculos para poucos indivíduos que podiam estar presentes assistindo. Todavia, o desenvolvimento da mídia criou formas de publicidade diferentes daquela tradicional baseada na co-presença. A característica fundamental destas novas formas é que, conforme aponta o autor (p.177), a notoriedade dos indivíduos, das ações e dos eventos não está mais limitada à partilha de um lugar comum. Os detentores do poder político ocupam-se agora também da sua auto-representação diante de um público não fisicamente presente e sempre maior. Eles passaram a desfrutar dos meios de comunicação não apenas para divulgar seus decretos, mas também como instrumento para construir uma imagem de si que pudesse ser transmitida para longe.

Por último, a interpretação dos títulos buscará identificar os pontos de fragilidade da visibilidade mediada, identificando também, de acordo com os casos propostos pelo autor, os limites de controle, tais como, as gafes, os escândalos e os excessos. ${ }^{6}$

\section{A história contada por la Repubblica: a ênfase no triunfo da esquerda brasileira}

O jornal la Repubblica publicou, de outubro de 2002 a agosto de 2003, 29 matérias específicas sobre Lula, sendo que 22 destas concentram-se no período de outubro a janeiro, abordando as eleições e a posse do novo governo. Em sua maioria, os textos publicados compõem páginas inteiras ou meias-páginas destacando o triunfo do novo líder de esquerda latinoamericano, com fotos mostrando Lula festejando e saudando o povo, beijando a bandeira brasileira, sorrindo, enfim, imagens centradas na pessoa dele mostrando momentos alegres.

Antes mesmo da vitória, o jornal já trazia em 1 o de outubro em meia-página o destaque: "Brasile, la sinistra di Lula vola verso la presidenza", incluindo uma entrevista exclusiva que Lula concedeu a jornalistas estrangeiros sobre a economia do país e as expectati- vas dos mercados financeiros frente a sua anunciada vitória. Logo após, no dia 5, a chamada de capa antecipava a vitória:"Stravince Lula è il presidente del Brasile". O texto de capa inicia afirmando que o "vermelho", numa alusão à esquerda, batia um recorde e, mais do que isso, Lula seria o primeiro operário a se sentar na cadeira dourada que até então havia hospedado somente a burguesia, remetendo, inclusive, ao imperador Dom Pedro II. Já a reportagem especial, no interior do jornal, revela que no Brasil "La stella di Lula convince industriali e senza terra", trazendo a última pesquisa de opinião, contrapondo Lula, candidato da esquerda, a José Serra, candidato do governo. No entanto, verifica-se que todo material produzido centra-se na figura de Lula, identificando-o como representante de "un nuovo Brasile". O texto, vale ressaltar, discute também o posicionamento dos Estados Unidos frente à economia mundial e o seu reflexo direto nos países emergentes. E, sobre este enfoque, aponta ainda o Brasil de Lula como, citando depoimento de Alain Touraine, "guia de um grande movimento mundial de negação da hegemonia norte-americana, aceita por grande parte do planeta". O repórter Guido Rampoldi conclui com a crítica de que este "presságio parece não ter nada em comum com a ânsia dos líderes e idéias fortes de uma esquerda ocidental que espera do exterior a nova direção, por não saber onde encontrar a sua própria". Ou seja, as esquerdas na Europa alimentam o consenso em novos lideres, como Lula, para buscar uma direção que eles mesmos desconhecem.

Já a matéria de página"Il Brasile sarà forte e solidale, con gli USA un rapporto alla pari" publicada em 06/ 10/2002, enfoca Lula como presidente praticamente eleito, trazendo curiosidades, tais como, a utilização das urnas eletrônicas, o voto aos 16 anos e dos índios da Amazônia, tabelas com estatísticas sobre desigualdade social, população, características do modo de governo presidencialista, sendo este material produzido por um correspondente no local.

Esta fase contempla outros exemplos de títulos de matérias publicadas em páginas inteiras: "Brasile, la vitória di Lula" (7/10/2002); "Lula parla da presidente" (8/10/2002); "Il Brasile che non ama l'America oggi punta tutto su Lula presidente" (27/10/2002); "Lula conquista il Brasile" (28/10/2002); "Lula rassicura i mercati il Brasile ce la farà'" (29/10/2002); por fim, textos ainda mais amplos como por exemplo aquele publicado sobre a posse - "Brasile, il giuramento di Lula: cambierò questo paese" (2/01/2003) - que aborda o plano de governo, a nomeação de ministros e a presença de Fidel Castro e Hugo Chavez na cerimônia em Brasília. A matéria identifica, também, projetos importantes como o Fome Zero e as reformas inevitáveis que o novo presidente terá que enfrentar: a agrária e a fiscal.

O período se encerra com a publicação "Lula riforma le pensioni in Brasile l'incantesimo resiste" (7/08/2003), página inteira escrita por um correspondente do jornal, o qual faz um balanço do primeiro semestre des- 
tacando que embora "l'economia brasiliana è in ginocchio, ma il miracolo Lula continua", isto é, demonstra que apesar de três entre quatro brasileiros continuarem acreditando no presidente, os índices econômicos não são tão otimistas. O repórter, que consultou várias fontes, entre elas, banqueiros e líderes dos movimentos sociais, afirma ter chegado a "hora da verdade" e que Lula teria poucos meses pela frente para não demonstrar "ter perdido uma oportunidade". Observa-se, deste modo, o início de uma nova fase, a de questionamentos, pois aquela do "risco Lula" já havia sido superada com o controle da economia e a adoção de uma política austera. O jornal anunciava que Lula chegava ao segundo momento do seu governo, ou seja, a "fase do desenvolvimento" e, conclui, novamente remetendo ao exemplo Europeu, identificando como ponto desfavorável, a coalizão entre partidos de centro e esquerda.

\section{Os questionamentos e gafes que ganharam visibilidade}

Nesta segunda fase, de setembro de 2003 a maio de 2005, verificaram-se 16 matérias publicadas sobre Lula e o seu governo. Entretanto, constatou-se que, além daquelas publicadas sobre as ações do governo, estiveram na pauta do jornal questões como a dos fazendeiros no norte do país e o trabalho escravo, a devastação da Amazônia e, principalmente, a participação de Lula nos fóruns sociais e econômicos ampliando para 62 o número de textos publicados, que citam o presidente brasileiro de algum modo. Limitamos esta análise, portanto, aos títulos mais expressivos sobre Lula e seu governo devido à delimitação desta pesquisa.

O jornal la Repubblica noticiou o caso do jornalista norte-americano que publicou um artigo no New York Times sustentando que o presidente Lula bebia muito. Com o título "Lula beve troppo, giornalista espulso" (13/ 05/2004), o diário passou a dar visibilidade as gafes cometidas por Lula diante das acusações de que o presidente brasileiro seria um "escravo do álcool".

O fato não somente ganhou as páginas do jornal, como também serviu de "gancho" para o correspondente, Maurizio Ricci, aprofundar o debate sobre a imagem do presidente. E, assim, em 20/6/2004, o diário publicou a chamada de capa: "Fra gaffes e programmi elettorali non mantenuti, l'immagine del presidente brilla sempre di meno". O texto nas páginas internas destaca que "l'economia è tornata a perdere colpi e a ottobre il paese voterà per le amministrative un referendum sul governo. L'uomo che in campagna elettorale annunciò il miracolo della crescita ora deve chiedere pazienza ai suoi elettori". Identificando diversos programas de governo e ações prometidas em campanha que não saíram do papel, com um texto nada positivo, o repórter apontou que Lula estava perdendo força por não ter conseguido atingir as metas e fazer deslanchar os programas sociais tal como o título resume: "Lula, le speranze tradite si incrina il sogno Brasiliano".
A visibilidade favorável ao presidente brasileiro obtida no primeiro período não é uma constante na cobertura jornalística nesta segunda fase, como comprova outra reportagem intitulada "Vittoria amara per Lula, alle amministrative perde i 'feudi' di San Paolo e Porto Alegre" (2/11/2004), que destacou como negativa a perda de dois centros petistas importantes nas eleições municipais. A mesma fragilidade é destacada em outra publicação: "Brasile, dopo un 2004 in rialzo le aspettative rimangono favorevoli" $(14 / 02 / 2005)$. Este período se conclui em abril de 2005 com a publicação de outras pautas, tais como a possibilidade do Vaticano eleger um Papa brasileiro e a criminalidade para com os índios.

Vale lembrar que neste período predomina ainda o enfoque na figura e identidade do presidente, mas difere ao apresentar os títulos e textos não mais a partir de uma expectativa otimista - "sonhos, milagres, brilho" -, mas de questionamentos sobre os programas sociais propostos e os rumos da economia.

\section{O escândalo dos votos comprados}

A fase mais atual inicia-se em 14/06/2005, com a publicação de uma matéria sobre a compra de votos no governo brasileiro e traz a palavra "escândalo" já no título: "Lula, lo scandalo dei voti comprati". De junho a agosto de 2005, são 18 títulos publicados que fazem referência a Lula e/ou Brasil, sendo que sete tratam das denúncias e os casos de corrupção envolvendo a equipe de governo.

Em $7 / 07 / 2005$, a publicação do texto intitulado "Brasile, Lula per superare la crise costretto al rimpiastro di governo" inicia com a pergunta, demonstrando um sentimento de traição até mesmo por parte do jornal: "quem poderia imaginar que o ex-operário metalúrgico eleito com o mais alto consenso jamais obtido por um candidato a presidência do Brasil estaria arriscando de deixar o palácio do Planalto por envolvimento em escândalo de corrupção política?" A matéria segue descrevendo as primeiras ações de Lula frente às denúncias de corrupção envolvendo dirigentes do PT e integrantes do governo, tais como o então Ministro da Casa Civil, José Dirceu. Observa-se uma lacuna entre o presidente e o partido no sentido em que o autor destaca que Lula "escolheu a linha dura" prometendo punir os culpados independentemente de partido. No entanto, revela o mesmo texto que "tudo seria admissível para os homens de Lula, até mesmo a adoção de uma política monetária de direita", mas "a corrupção não", remontando brevemente a trajetória do partido. Nota-se, portanto, a imagem de Lula frágil, mas nem tanto abalada.

Cinco dias depois, o jornal traz além de ampla matéria em página interna, a seguinte chamada de capa: "Per le accuse di corruzione - Brasile, Lula in lacrime chiede scusa in televisione" (13/08/2005). Ao descrever o discurso do presidente em cadeia nacional, no qual, em lágrimas, pediu desculpas aos eleitores, o diário retoma as acusações, as denúncias e as descobertas 
das investigações apontando ser impossível que o presidente desconhecesse as ações de corrupção desenvolvidas pelo seu partido e homens de confiança. O texto cita inclusive a confirmação, por parte do publicitário Duda Mendonça, de depósitos efetuados em paraísos fiscais pelo partido em seu benefício. Enfim, esta publicação rompe com a confiança e a idéia de que o presidente foi ingênuo. Ao comparar Lula e seu partido ao ex-presidente Fernando Collor de Mello, destaca o risco de um possível processo de impeachment. Fato retomado em 19/08/2005 com o título Brasile, la solitudine di Lula sfida disperata per la rielezione, ao ressaltar que, após o escândalo de corrupção compra/venda de parlamentares, a oposição renuncia ao impeachment para se concentrar na campanha eleitoral de 2006.

A presente fase se conclui em $25 / 8 / 2005$, última matéria publicada no mês de agosto que delimita esta pesquisa, sob o título "Lula sempre in crisi, se si votasse oggi perderebbe le elezoni". Identifica-se no texto elementos de parcialidade por parte do jornal em favor de Lula, por exemplo, ao apresentar a pesquisa IBOPE para presidência do Brasil, o autor da matéria enfatiza duas "notícias". A positiva, referindo-se ao fato de que Lula teria mais chances de vencer as eleições no próximo ano caso José Serra não for seu principal concorrente; e a negativa, que em pouco menos de dois meses a popularidade de Lula havia caído de 52 para 43 devido às denúncias de corrupção. Verificando-se assim, uma atitude parcial do jornal em benefício da figura de Lula. A seguir, o presente artigo passa a analisar o diário Corriere della Sera, com o objetivo de estabelecer uma comparação entre as duas linhas editoriais enriquecendo, assim, este pesquisa.

\section{A versão do Corriere della Sera: a ênfase na realidade brasileira}

Nem tanto "otimista", nem tanto "desconfiada", talvez "ponderada" seria a melhor definição para a cobertura do Corriere della Sera da eleição do novo governo brasileiro em 2002. Este jornal apresenta características diferentes de la Repubblica, embora reúna também um número expressivo de publicações no período. Somente nesta primeira fase, de outubro de 2002 a agosto de 2003, foram 54 matérias publicadas, sendo que 41 destas no período eleitoral e de posse do governo Lula.

Antecipando as eleições, o diário italiano publicou "Brasile, la sinistra di Lula vola verso la presidenza; Basta lacrime e carnevale, con me il Brasile diventerà forte" (01/ 10/2002); "Effetto Brasile mercati in ansia" (04/10/ 2002); entre outros títulos, tais como: "Il dolce Brasile sogna la tolleranza zero" (05/10/2002) cujo texto discorre sobre o poder do narcotráfico e a preparação das forças policiais para manter a ordem durante as eleições de primeiro turno; "Brasile al voto, Lula prepara la squadra" (06/10/2002) destaca Lula praticamente eleito e os mercados financeiros entregues ao sucesso da esquerda. Estes exemplos demonstram que, de modo geral, embora a cobertura jornalística seja, também, centrada na figura de Lula, os destaques privilegiados são relacionados à economia, à identificação do candidato com a esquerda, a elementos da identidade brasileira e à segurança pública.

No dia seguinte, em $07 / 10 / 2002$, são publicadas duas páginas sobre as eleições no Brasil. As pautas das matérias descrevem a votação conforme o cotidiano do Rio de Janeiro, trazem entrevistas com o arquiteto Oscar Niemeyer, moradores das favelas e freqüentadores das praias cariocas. Em nenhum momento relata projetos de governo de qualquer candidato, embora relacione sempre os principais, além de Lula, José Serra, Anthony Garotinho e Ciro Gomes.

"L'ex 'barbudo' che ha imparato a sorridere in TV (07/ 10/2002) ilustra esta característica e diverge do que foi descrito anteriormente e publicado, em igual período, no outro diário italiano. O Corriere della Sera, por seu turno, aponta uma perspectiva otimista centrada na realidade brasileira, ou seja, na esperança do povo por mudanças e não por "milagres". Ao abordar Lula como "quase" presidente, a referida matéria descreve sua trajetória, bem como a do PT, destacando também os dois pontos de vista da população. Identifica, de um lado, aqueles que não o amam, embora o enxerguem como um homem honesto, exaltam que o fato de Lula não ter trabalhado um só dia em sua vida, o torna incapaz de governar o país. De outro lado, aponta aqueles que votam nele por acreditarem ser o único político capaz de escutar os dramas nacionais porque os conhece. O texto identifica, inclusive, Duda Mendonça como o "gênio" do marketing, que refez a imagem de Lula para lidar com a mídia. Esta página apresenta outro texto de apoio redigido pela redação de Roma (e não mais pelo correspondente Rocco Crotoneo, do Rio de Janeiro, que produz a maioria dos textos). "La sinistra tutta con lui, da Veltroni all'amico Sergio" apresenta diversas fontes da esquerda italiana que demonstram consenso na aproximação de Lula ao reformismo da mesma na Europa. Vale lembrar que a cobertura traz freqüentemente cartolas (Brasile alle urne/La sfida di Lula), pesquisas de opinião, fotos dos candidatos, gráficos e dados estatísticos sobre o país, bem como comparações do tipo:"Due mondi vicini e separati / Ipanema: la spiaggia si diverte / Rocinha: nella favela, occasione per un pasto".

Em 08/10/2002, outra característica interessante, o jornal, embora reconheça Lula como candidato praticamente eleito para o segundo turno, publica duas meias-páginas sobre o resultado das eleições de primeiro turno dando igual espaço a Lula e ao candidato Anthony Garotinho. Com o título "Brasile, l'irresistibile ascesa degli evangelici" coloca em pauta a crescente perda de fiéis da Igreja Católica para protestantes e evangélicos. Somente na outra meia-página que o texto "Brasile, per Lula 'cominciano i supplementari' trata do resultado das urnas apontando Lula como favorito, porém publica outros dois secundários: "Il secondo posto di José Serra politico serio ma senza carisma" e, um 
box, para o candidato Enéas Carneiro "Un milione di voti al medico matto".

Lula passa a centralizar a cobertura com a proximidade do segundo turno. Em 26/10/2002, o jornal anuncia que "Lula non spaventa più il Brasile" e que apesar das pesquisas apontarem para a vitória, os índices econômicos se estabilizaram. "Il mio Brasile rialzerà la testa" (27/10/2002) é a manchete da eleição da edição que publica uma entrevista com Lula e destaca somente questões como o controle da economia, a relação com o Fundo Monetário Internacional (FMI) e a geração de produtividade e riquezas.

Nada de projetos ou programas sociais na matéria de página que anuncia a vitória de Lula, mas análises para o futuro da economia e a fragilidade dos mercados diante a transição: "Lula trionfa, è il nuovo presidente del Brasile" (28/10/2002) destaca "números" votos, eleitores, habitantes, renda per capita, etc. A cobertura traz ainda duas entrevistas ponto-a-ponto, uma com o empresário Giorgio della Seta, presidente da Pirelli, em São Paulo, e a outra com o escritor Paulo Coelho, ambos demonstram otimismo no novo governo. No dia seguinte, 29/10/2002, sob o título "Lula: eliminarò la fame dal Brasile" em meia-página o correspondente Rocco Crotoneo, pela primeira vez, ao relatar o discurso de Lula como presidente, faz referência aos programas sociais, abrindo o texto com a seguinte declaração: "prima colazione, pranzo e cena. Per tutti. Questo è il mio sogno. Se alla fine del mio mandato, ogni brasiliano riuscirà a mangiare tre volte al giorno, io avrò realizzato l'obbiettivo della mia vita".

O jornal volta a dar destaque ao presidente brasileiro em janeiro de 2003, por ocasião dos fóruns Social Mundial e Econômico, quando ele assume, através das coberturas dos eventos, o papel de porta-voz dos menos favorecidos, conforme os títulos verificados: "Dirò ai potenti: il mondo si può cambiare" (25/01/ 2003) e ainda "Lula chiede ai 'potenti' un patto contro la fame" (27/01/2003).

Esta fase se conclui quando, efetivamente, o diário dá início aos questionamentos ao governo publicando já em 21/02/2003 "Brasiliani dellusi da Lula? La crise e $i$ venti di guerra frenano il neo-presidente". E, também, ao retomar em 03/8/2005, "Senza Terra e recessione assediano Lula". Nesta primeira fase é importante destacar que o Corriere della Sera, ainda que otimista diante da vitória do novo governo, enfatizou mais a necessidade de manter a estabilidade da economia brasileira do que as promessas de mudanças sociais propostas por Lula.

\section{Visibilidade em acusações}

Neste período intermediário ao da crise, de setembro de 2003 a maio de 2005, os questionamentos são ainda mais evidentes na cobertura realizada pelo Corriere della Sera. Os arquivos identificam 34 matérias sobre o Brasil em geral, sendo 13 específicas sobre o presidente e o governo, com exceção de um universo maior de pautas sobre cultura, esporte e a própria América
Latina, que ampliam para mais 69 o número de textos que, de algum modo, citam o nome de Lula.

"Lula è un neoliberal" publica o jornal em 03/9/ 2003; "Sinistra italiana: è già finito l'amore per Lula?" anuncia em 10/9/2003; "Il nuovo corso di Lula vira al centro" (25/1/2004); estes textos questionam e fazem um balanço do primeiro ano de governo. Neste último, vale destacar que o repórter descreve a reforma ministerial identificando a entrada de membros de partidos moderados de centro, como o PMDB, antigo rival do PT, e a saída de companheiros de Lula do governo.

Além disso, relembra a promessa não cumprida, de que após um ano de gestão com sacrifícios e políticas rígidas para a economia, se chegaria ao social com a efetivação do programa Fome Zero.

O Corriere della Sera, igualmente ao la Repubblica, dá visibilidade à gafe ocasionada pela expulsão do jornalista norte-americano ao referir-se a Lula como um alcoólatra, publicando duas matérias sobre o assunto: "Lula infiurato con il New York Times" (11/5/2004) e "Lula beve, reporter espulso" (13/5/2004).

Em novembro, o diário destaca também a perda do PT em capitais importantes nas eleições municipais em matéria intitulada "Lula perde San Paolo e le città 'borghesi' del Brasile" (02/11/2004). Esta fase se encerra com destaques negativos sobre o presidente: "Lula scopre che la fame non è una priorità. Quattro brasiliani su dieci oggi sono grassi" (20/12/2004); "Con Lula il Brasile cavalca le illusione" (30/12/2004); durante o Fórum Social "Porto Alegre difende Lula dai contestatori" (28/01/2005) e "Hugo trionfa tra i no global. Lula abbandonato dai suoi" (02/02/2005); por fim, o descaso com o meio ambiente "Brucia l'Amazzonia. Greenpeace accusa Lula" (20/5/2005).

\section{A telenovela de Lula}

O Corriere della Sera noticia o escândalo de corrupção no governo brasileiro no dia 7/6/2005 quando publica "Governo Lula sott'accusa: stipendia i deputati perchè votino a comando". Desta data até o final de agosto de 2005, são 13 matérias sobre a crise, num total de 24 publicadas sobre o Brasil.

"Si dimette il capo del partito di Lula" (10/7/2005) anuncia o jornal ao referir-se a demissão de José Dirceu; "Via il tesoriere" (6/7/2005); "Deputato fermato con 7 valigie di soldi" (12/7/2005); "Fondi illegali, il partito del presidente ammette" (18/7/2005); estes textos relatam as acusações e a sucessão de escândalos envolvendo políticos e integrantes do governo Lula.

Em 05/8/2005, com a publicação "E lo scandalo di Lula ora è una telenovela", o diário compara o escândalo envolvendo o presidente brasileiro a uma telenovela, pois reúne características semelhantes, tais como, o alto índice de audiência registrado nos canais de transmissão ao vivo das Comissões Parlamentares de Inquérito, corrupção, mulheres, amantes, etc. A matéria produzida pelo correspondente Rocco Crotoneo revela, ainda, um Brasil paralisado diante da televi- 
são e a amplia com o exemplo italiano "como se nos tempos da Mãos Limpas (operação), a televisão estivesse dentro do escritório de Di Pietro". Observa-se neste texto novamente elementos de identidade brasileira.

Sob o título "Corruzione, Lula in TV: brasiliani perdonatemi" (13/8/20025) o jornal relata o discurso realizado em cadeira nacional pelo "presidente dos trabalhadores", referindo-se, deste modo, a Lula com ironia. Principalmente porque a matéria aponta que o presidente se diz "traído" por integrantes da equipe de governo e de seu partido envolvidos em revelações cotidianas de corrupção e que, por isso, arrisca um processo de impeachment.

\section{Considerações finais}

A presente pesquisa em nenhum momento buscou avaliar o desempenho do governo do presidente Luis Inácio Lula da Silva, mas realizar uma análise qualitativa sobre a transformação da sua visibilidade nos principais jornais diários da Itália desde a sua eleição até a crise revelada em junho de 2005. Por tratar-se de um artigo foi necessário adotar uma delimitação mais rigorosa, ou seja, a de analisar os títulos publicados; no entanto, em alguns casos considerou-se necessário descrever o conteúdo dos textos pela riqueza de informações. Contudo, o desenvolvimento metodológico deste artigo deu-se em três níveis, os quais podem servir de ponto de partida para novos estudos na área.

O primeiro buscou identificar o papel do Brasil no cenário externo, neste caso, o italiano. Sobre este aspecto, ainda que de maneira incipiente, verificou-se que a participação do país na lógica de mercado globalizada está presente na maioria dos textos publicados, pois ambos jornais dão ênfase à situação econômica e ao reflexo nos mercados interno e externo. Embora o diário la Repubblica, principalmente, no período eleitoral e de posse do governo Lula, tenha destinado espaço, também, aos programas sociais propostos.

O segundo nível constatou que era possível contextualizar em períodos o material publicado pelos dois diários. Neste sentido, a comparação entre eles foi inevitável, pois apresentaram algumas características comuns e outras divergentes. Entres as principais semelhanças estão: a periodização em fases; a valorização e o aprofundamento das pautas, no sentido em que enviaram correspondentes especiais ao Brasil para produzirem a maioria do material publicado; e a ênfase em Lula, na sua identidade, ou seja, os textos, na maioria das vezes, centram-se na imagem dele. As diferenças ficam por conta das linhas editoriais. $\mathrm{O}$ jornal la Repubblica centrou-se mais nas questões sociais, foi mais "otimista", quase parcial, em alguns momentos, com relação ao governo de Lula, porém mostra um Brasil mais unitário. Já o Corriere della Sera é mais "ponderado" ao apresentar aos italianos o "milagre Lula", no entanto, descreve as questões brasileiras a partir do universo de identidade carioca.

O terceiro e último nível trouxe para a pesquisa empírica a perspectiva teórica proposta por Thompson que, durante todo o processo de construção, permeou a análise. Neste sentido, a categoria "transformação da visibilidade" e suas implicações permitiram que viessem à tona elementos importantes. $\mathrm{O}$ fenômeno Lula, por exemplo, ganhou visibilidade global através da mídia e a imprensa italiana comprova isso, pois noticia, ainda que em proporção menor, se relacionado à imprensa nacional, as principais ações do presidente Lula. A presente pesquisa identifica, também, que toda a visibilidade ganha pelo presidente foi positiva à imagem dele na fase inicial do governo e que esta, devido aos excessos cometidos, ou seja, promessas de diminuição da desigualdade social não realizadas passam, a partir da segunda fase, a levantar o que o autor identifica como " pontos de fragilida$\mathrm{de}^{\prime \prime}$, tais como as gafes e os próprios excessos. Por exemplo, foi visto que a publicação do New York Times e um simples gesto do presidente geraram notícias e estas se transformaram em agente ativo do jogo político. Por fim, o escândalo dos votos e a crise desencadeada pelas denúncias de corrupção envolvendo integrantes do governo e do partido de Lula. Fatos que repercutiram negativamente em ambos jornais finalizando o sonho que, no cenário italiano, eles próprios ajudaram a construir. mfamecos

\section{NOTAS}

1 A escolha dos principais jornais italianos - la Repubblica e Corriere della Sera - para análise devese a este questionamento e, também, por serem os dois jornais diários de maior tiragem da Itália (respectivamente 659.957 e 686.259 cópias). Estes diários apresentam linhas editoriais diferentes. $\mathrm{O}$ primeiro, fundado em 1976, é voltado para um público de centro-esquerda, elabora pautas enfatizando mais questões sociais do que econômicas. O segundo, fundado em 1876, direciona-se a políticas de centro, ou seja, de cunho mais econômico, de mercado.

2 Os arquivos on-line de alguns jornais europeus registram o número de textos publicados sobre o presidente Lula de outubro de 2002 a agosto de 2005: Le Monde (500); Le Figaro (480), El Mundo (424), The Guardian (149) e The Times (51).

3 O artigo de Berger e Motta (2003a) sobre as eleições brasileiras nos jornais espanhóis não somente comprova este fato, como também evidencia a ênfase na imagem de Lula. Os autores concluem que o fenômeno deveria ser analisado com mais profundidade, pois o estudo mostra que a imprensa espanhola deu mais visibilidade as eleições brasileiras do que as turcas, alemãs e francesas desenvolvidas no mesmo período e mais próximas geograficamente. Os jornais espanhóis mostraram varias fontes: mercado, investidores e políticos tradicionais. 
4 Conforme pesquisa CNT/Sensus publicada na revista Veja, 21 de setembro 2005, p.51.

5 Sobre este aspecto é interessante ver também outro artigo de BERGER, Christa \& MOTTA, Luiz Gonzaga (2003b): Narrativa jornalística: a história de Lula contada pelos jornais espanhóis. In: Revista Famecos. Mídia, cultura e tecnologia. Porto Alegre: PUCRS, n.21, agosto, pp. 90-109.

6 A definição do autor para estas categorias encontra-se no quarto capítulo: La transformazione della visibilità, da página 197 a 209. In: THOMPSON, John B. (1998) Mezzi di comunicazione e modernità. Una teoria sociale dei media. Bologna: Il Mulino.

\section{REFERÊNCIAS}

ADORNO, T. \& HORKHEIMER, M. (1966). Dialettica dell'illuminismo. Torino: Einaudi.

BERGER, Christa \& MOTTA, Luiz Gonzaga (2003a). Cobertura das eleições brasileiras pela imprensa espanhola: Lula põe a esquerda na pauta. In: Comunicação \& Política. Rio de Janeiro: Abec/ Unesco. V.x, n.1, janeiro-abril, pp. 11-35.

BERGER, Christa \& MOTTA, Luiz Gonzaga (2003b). Narrativa jornalística: a história de Lula contada pelos jornais espanhóis. In: Revista Famecos. Mídia, cultura e tecnologia. Porto Alegre: PUCRS, n.21, agosto, pp. 90-109.

CANCLINI, Néstor García (1995). Consumidores e cidadãos - conflitos multiculturais da globalização. Rio de Janeiro: Ed. UFRJ.

DALPIAZ, Jamile (2001). Cidade Viva: o rádio e a política na tradução de um governo. In: RAMOS, Roberto (Org.). Mídia, textos \& contextos. Porto Alegre: EDIPUCRS, pp.75-98.

DEBORD, Guy (1979). La società dello spettacolo. Firenze: Vallecchi.

DAMATTA, Roberto (1998). O que faz o brasil, Brasil? Rio de Janeiro: Rocco.

EMPOLI, Giuliano da (2005) Fuori controllo. Tra edonismo e paura: il nostro futuro brasiliano. Venezia: Marsilio Editori.

GOMES, Neusa D. (2000). Formas persuasivas de comunicação política - propaganda política e publicidade eleitoral. Porto Alegre: EDIPUCRS.

GOMES, Wilson (1999). A política de imagem. In: Revista Fronteiras. Vol I, n.1, São Leopoldo: Unisinos, pp.43-52.
(1995). "Theatrum Politicum": a encenação da política. In: BRAGA, José Luiz et alli (org). A encenação dos sentidos - mídia, cultura e política. Rio de Janeiro: Diadorim.

_ (1994). As astúcias da política. Salvador, UFBA/ COMPÓS.

HABERMAS, Jurgen (1984). Mudança estrutural da esfera pública. Trad. F. Kothe. Rio de Janeiro: Tempo brasileiro.

(1974). Storia e critica dell'oppinione pubblica. Bari: Laterza.

HAUSSEN, Dóris F. (1997). Rádio e Política: tempos de Vargas e Perón. Porto Alegre: Edipucrs.

KUCINSKI, Bernardo (2000). As cartas ácidas da campanha de Lula de 1998. Cotia (SP): Ateliê Editorial.

MAFFESOLI, Michel (1997) A transfiguração do político. A tribalização do mundo. Porto Alegre: Sulina.

MATA, Maria Cristina (1992). Entre la plaza y la platea. In: SCHMUCLER, H. \& MATA, M. C. (org.) Política y comunicacion - Hay un lugar para la política en la cultura mediática? Buenos Aires: Universidad Nac. de Córdoba/Catálogos.

MURCIANO, Marcial (1999). As políticas públicas de comunicação na Europa. In: Para navegar no século XXI. Tecnologias do imaginário e cibercultura. MARTINS, Francisco \& SILVA Juremir Machado da (orgs). Porto Alegre: Sulina.

RUBIM, Antônio C. (2000) Mídia e Eleições de 1998. Salvador: UFPB/UFBA.

RUBIM, Antônio C. (1994). Mídia e política: transmissão de poder. In: MATOS, Heloiza (org.). Mídia, eleições e democracia. São Paulo: Página Aberta.

RUBIM, Antônio C. (2002). Nuove configurazione delle elezioni nell'Età dei Media in Brasile. In: BECHELLONI, Giovani \& LOPES, Maria Immacolata V. Dal controllo alla condivisione. Studi brasiliani e italiani sulla comunicazione. Firenze: AILAC e Mediascape, pp.167-182.

SODRÉ, Muniz (1984). A máquina de fazer narciso televisão, indivíduo e poder no Brasil. Rio de Janeiro: Achiamé.

SORRENTINO, Carlo (1999). Cambio di rotta. Temi e tendenze del giornalismo italiano. Napoli: Liguori. 
- (2001). Geometrie variabili. Luoghi, forme e strategie di comunicazione politica. Napoli: Ipermedium Libri.

_. (2002). Il giornalismo. Cos'è e come funziona. Roma: Carocci Editora.

_ . (2002). Nuove forme di comunicazione politica in Italia. In: BECHELLONI, Giovani \& LOPES, Maria Immacolata V. Dal controllo alla condivisione. Studi brasiliani e italiani sulla comunicazione. Firenze: AILAC e Mediascape, pp.191-200.

SCHUDSON, Michael (1988) La scoperta della notizia. Napoli: Ligori.

SCHUDSON, Michael (1999) The good citizen. Cambridge: Harvard University Press.

THOMPSON, John B. (2000) Ideologia e cultura moderna. Teoria social crítica na era dos meios de comunicação de massa. $5^{\text {a }}$ ed. Petrópolis: Vozes.

_ (1998) Mezzi di comunicazione e modernità. Una teoria sociale dei media. Bologna: Il Mulino.

- (2000) Political Scandal - Power and visibility in the media age. Cambridge [UK], Polity Press.

WEBER, Maria H. (2000). Comunicação e espetáculos da política. Porto Alegre: Ed.Universidade/ UFRGS.

WEBER, Maria H. (2002). Comunicazione come strategia di condivisione del potere. In: BECHELLONI, Giovanni \& LOPES, Maria Immacolata V. Dal controllo alla condivisione. Studi brasiliani e italiani sulla comunicazione. Firenze: AILAC e Mediascape, pp.213-230.

WEBER, Maria H. (1994). Delitos estéticos. A política na televisão. In: NETO, Fausto (org.). Brasil, comunicação, cultura \& política. Rio de Janeiro: Diadorim.

WEBER, Maria H. (1999). Política, refém da imagem pública. In: Pimenta, Marcelo.../ et al. Porto Alegre: L\&PM/RBS, pp.70-85. 